\title{
Assessing Knowledge and Attitudes Regarding Pain Management Among Nurses Working in a Geriatric Hospital in Vietnam
}

This article was published in the following Dove Press journal: Journal of Multidisciplinary Healthcare

Anh Trung Nguyen, ${ }^{1,2}$ Anh Kim Dang, ${ }^{3}$ Huong Thi Thu Nguyen, (D) I,2,4 Thanh Xuan Nguyen, (D) ${ }^{1,2}$ Tam Ngoc Nguyen, (D) I,2 Thu Thi Hoai Nguyen, (D) ${ }^{1,2}$ Thang Pham, ${ }^{1,2}$ Anh Lan Nguyen, ${ }^{1,2}$ Thuy Thi Ngoc Nguyen,' Hien Nguyen Thi, 5,6 Trang Ha Nguyen, ${ }^{5,6}$ Son Hoang Nguyen, ${ }^{7}$ Bach Xuan Tran, ${ }^{3,8}$ Carl Latkin, (D) ${ }^{8}$ Roger CM Ho, (D) 9,10 Cyrus SH Ho, iD "' Huyen Thi Thanh Vu iD ${ }^{1,2}$

'Department of Geriatrics, Hanoi Medical University, Hanoi, I00000, Vietnam;

${ }^{2}$ Scientific Research Department, National Geriatric Hospital, Hanoi, I00000, Vietnam; ${ }^{3}$ Institute for Preventive Medicine and Public Health, Hanoi Medical University, Hanoi, 100000, Vietnam; ${ }^{4}$ Dinh Tien Hoang Institute of Medicine, Hanoi, 100000, Vietnam; ${ }^{5}$ Institute for Global Health Innovations, Duy Tan University, Da Nang, 550000 , Vietnam; ${ }^{6}$ Faculty of Nursing, Duy Tan University, Da Nang, 550000, Vietnam; ${ }^{7}$ Center of Excellence in Health Services and System Research, Nguyen Tat Thanh University, Ho Chi Minh, 700000, Vietnam; ${ }^{8}$ Bloomberg School of Public Health, Johns Hopkins University, Baltimore, MD, 2I205, USA; ${ }^{9}$ Department of Psychological Medicine, Yong Loo Lin School of Medicine, National University of Singapore, Singapore, I 19228, Singapore; ${ }^{10}$ Institute for Health Innovation and Technology (iHealthtech), National University of Singapore, Singapore, I 19228, Singapore; "'Department of Psychological Medicine, National University Hospital, Singapore, I19228, Singapore

Correspondence: Anh Trung Nguyen Geriatrics Department, Hanoi Medical University, No I Ton That Tung, Dong Da, Hanoi, I00000, Vietnam

Tel +84903480774

Email trunganhvlk@gmail.com
Background: Nurses play a pivotal role in pain management. Knowing more about nurses' knowledge and attitudes regarding pain is important as we develop multidisciplinary pain services. Therefore, this study aimed to assess knowledge and attitudes regarding pain management among nurses in a geriatric hospital and its associated factors.

Subjects and Methods: A survey was conducted of nurses worked at the National Geriatric Hospital over a 3-month period. The Knowledge and Attitudes Survey Regarding Pain (KASRP) was utilized to assess nurses' knowledge and attitudes toward pain management. Four domains were defined based on KASRP, included cancer-related pain, pain assessment, pharmacology and substance abuse and physical dependence. Knowledge and attitudes regarding pain were classified as poor, fair, or good $(\leq 50 \%, 50 \%-75 \%$, or $\geq 75 \%$ of the KASRP score). Multivariate Tobit regression models were applied to identify factors associated with the knowledge and attitudes regarding pain management.

Results: Of 154 participants completed the survey, 72.2\% (111 participants) had poor knowledge and attitudes regarding pain management. The participants had a correct mean score of $45.2 \%(\mathrm{SD}=2.2)$. Nurses' knowledge of pain assessment was poor, with the proportion of correct answers to nine questions ranging from $2.6 \%$ to $50 \%$. $44.8 \%$ of nurses reported never or rarely using pain assessment tools. Nurses who had previous training regarding pain at medical universities had significantly higher scores of knowledge and attitudes compared to those without training. Nurses who often use pain assessment tools had a significantly higher level of knowledge and attitudes than those who never or rarely use them.

Conclusion: This study highlights significant deficits of knowledge and negative attitudes regarding pain management among nurses. The subject of pain management should be applied and enhanced in the nursing undergraduate curriculum. Nurses' active participation in pain management should be encouraged by healthcare providers for older patients.

Keywords: knowledge, attitude, nurse, pain management, older people

\section{Introduction}

The number of older people with pain is going to increase in Vietnam as it is due to experience one of the fastest increases in older people in the world. ${ }^{1,2}$ In 2017 , Vietnam had an estimated 10 million adults aged over 65 and this is expected to rise to 19 million by 2030 and 28 million by $2050 .^{3}$ Persistent pain is a common health issue among older adults, with the prevalence ranging from $45 \%$ to $80 \%$ in the community. ${ }^{4-6}$ The presence of pain and inadequate pain management is associated with the deterioration of existing health conditions, as well as functional 
impairment, falls, depression, decreased appetite, impaired sleep, social isolation, and low quality of life, particular in older people. ${ }^{7,8}$ It is therefore important that healthcare professionals who provide care for older people have the knowledge and skills to carefully evaluate and manage pain. Pain assessment and management of older people is complicated due to factors such as co-existing cognitive impairment, multi-morbidity, poly-pharmacy, and vulnerability to the potentially harmful adverse effects of analgesics and drug interactions. ${ }^{9,10}$

Multidisciplinary pain services provide a multidisciplinary approach to pain management. In practice, the core team consists of three types of physicians (primary care physicians, anesthesiologists, and psychiatrists) and non-physicians (psychologists, physiotherapists, and nurses). Nurses are a key member of the multidisciplinary team in healthcare facilities that specialize in providing health care to older people. ${ }^{11}$ Nurses play a pivotal role in treating pain effectively through accurate assessment, timely intervention, and the evaluation of pain relief interventions. A high level of knowledge about pain assessment and management and positive attitudes regarding pain management in nurses are considered critical factors in providing effective pain management. ${ }^{12,13}$ Previous study in the hospital setting have shown deficiencies in nurses' knowledge of pain and pain management. ${ }^{14}$ In a study about geriatric palliative care that was not focused on pain, we found that nurses had insufficient knowledge about pain management in this specific setting. ${ }^{15}$ Apart from this study, few empirical studies have focused on nurses' knowledge and attitudes regarding pain management in Vietnam. Thus, our study aimed to assess knowledge and attitudes regarding pain management among nurses in the National Geriatric Hospital and identify factors that influence knowledge and attitudes to pain management. The findings from this study can shed light on how the management of pain curriculum in educational courses for health staff needs to be developed.

\section{Materials and Methods}

\section{Study Setting and Participants}

A study was conducted at the National Geriatric Hospital from April to October 2018. The National Geriatric Hospital is the highest-level hospital in the system of medical examination, treatment, and health care for older people in Vietnam. All registered nurses working full-time in the clinical departments (12 departments) of the
National Geriatric Hospital for at least 6 months were invited to participate in the study.

\section{Measures and Instruments}

The survey consisted of a self-administered questionnaire. Participants answered the questions by themselves in the presence of the investigator. The final version of the survey questionnaire included the following:

\section{Socio-Economic Characteristics}

Age, gender, educational level, marital status, and years of work as a nurse.

Pain management skills: whether they attended a formal or informal course on pain management, types of courses, and frequency of use of pain assessment tools on hospital wards.

\section{Knowledge and Attitudes Survey Regarding Pain (KASRP)}

The Knowledge and Attitudes Survey Regarding Pain (KASRP) was utilized to assess nurses' knowledge and attitudes toward pain management. The KASRP was developed by Ferrell and McCaffery in 1987 and has been used frequently since then. ${ }^{16}$ The KASRP has been validated in many previous studies on medical staff and nurses of various levels of expertise, such as students, new graduates, oncology nurses, geriatric nurses, graduate students, and senior pain experts. ${ }^{12-14,17}$ The content of KASRP is derived from the current standards of pain management from the American Pain Society, the National Comprehensive Cancer Network Pain Guidelines and the World Health Organization. A panel of pain experts has established content validity. The testretest reliability of the KASRP has been established ( $\mathrm{r}>0.8$ ), and the internal consistency, or reliability, using Cronbach's alpha has been measured $(>0.7$ in both knowledge and attitude domains). ${ }^{18}$

We applied a standardized process for developing the Vietnamese version of a subset of KASRP to use in the study. First, we conducted a forward - backward translation from English into Vietnamese involving an English translator, geriatricians, pain doctors, anesthesiologists, psychiatrists, and a representative of nurses. Any discordance emerging from the translation and reviews was discussed among the team and we produced the translated version of the tool. Secondly, we piloted this version among a small sample of 20 nurses. This pilot was to (1) assess the feasibility of using the translated tool among 
this group of nurses, including - administered methods, time, and flow, and (2) rapidly assess nurses' responses to understand if there were any factors affecting the validity of the measurement, eg, understanding of the questions. Finally, we conducted a post-pilot review among the research team to finalize the Vietnamese version of the questionnaire to be applied.

The finalized version of the KASRP consisted of 39 questions, which included 22 "true or false" questions, 15 multiple-choice questions, and 2 case studies (with part $\mathrm{a}$ and $\mathrm{b}$ for each case). Each correct question was marked as 1 point. Two case studies with issues from real-world experiences of assessing and reassessing a patient were presented for which participants had to evaluate the pain of patients based on a numerical pain rating scale (0 (no pain/discomfort) to 10 (worst pain/discomfort)) and then decide on whether to prescribe intravenous (IV) morphine and if so at what dose for continued pain 2 hours after the previous IV morphine dose.

The KASRPs' authors suggested that the analysis should avoid distinguishing items as measuring either knowledge or attitudes ${ }^{16}$ and they recommended that the scores be presented as the percentage as a percentage of correct responses. Besides calculating the total score of the KASRP, 4 domains within the tool were also defined, which were cancer-related pain (Q05, Q23, Q25, Q28, Q30), pain assessment (Q01, Q02, Q03, Q04, Q12, Q31, Q32, Q38a, Q39a), pharmacology (Q06, Q07, Q08, Q09, Q10, Q11, Q13, Q14, Q15, Q16, Q17, Q18, Q19, Q21, Q24, Q26, Q27, Q29, Q34, Q35, Q37, Q38b, Q39b), and substance abuse and physical dependence (Q20, Q22, Q33, Q36). The level of nurses' knowledge and attitudes regarding pain was classified as follows: Poor $(\leq 50 \%$ of the KASRP total score), Fair $(50-75 \%$ of the KASRP total score), and Good ( $\geq 75 \%$ of the KASRP total score). ${ }^{16,19}$

\section{Data Analysis}

All analysis was done using STATA software version 12 (Stata Corp. LP, College Station, United States of America). Descriptive statistics for participant characteristics are presented as mean $\pm \mathrm{SD}$ for continuous variables and frequency/percentages for categorical variables. Because the KASRP score ranges from 0 (all answers are false) to 41 (all answers are true), multivariate tobit regression models were applied to examine the factors associated with the total KASRP score. The tobit model is also called a censored regression model and aims to estimate linear relationships between variables when there is either left- or right-censoring in the dependent variable. To identify the reduced regression model, we conducted a forward stepwise selection strategy with a threshold of less than 0.2. Statistical significance was considered when $\mathrm{p}<0.05$.

\section{Results}

A total of 178 nurses initially agreed to take part in the study of whom 154 returned completed surveys to the investigator (a response rate of $86.5 \%$ ). Table 1 shows the demographic characteristics of the study participants. The mean age of the participants was 29.1 years $(\mathrm{SD}=5.9)$ and $79.9 \%$ were female. On average participants had 5.6 years $(\mathrm{SD}=4.4)$ of nursing work experience and one-third had graduated from university. Table 1 also shows the responses to the questions on pain management skills. The percentage of participants who attended a formal course on pain was $57.1 \%$. About $66.9 \%$ and $15.6 \%$ of participants self-assessed that they had average and good skills in pain management, respectively.

Table 2 shows the overall KASRP knowledge and attitude results and the percentage of participants with correct responses to each KASRP question. The majority of participants were classified as having poor knowledge and negative attitudes (72.2\%). The average score of percentage for the group was $45.2 \%$ ( $\mathrm{SD}=2.2$ ). Regarding cancer-related pain, most of the nurses knew the type of analgesic medications used for prolonged pain in cancer patients $(83.1 \%)$, and the analgesic medications useful for the treatment of cancer pain (63.4\%). However, only $5.8 \%$ of participants had adequate knowledge about the recommended route of opioid analgesic administration for those with persistent cancer-related pain. For all the nine items in the pain assessment section, $50 \%$ or less gave a correct answer. As for the question on which of five options was the correct answer for the "the most accurate judge of the intensity of the patient's pain", only $25.3 \%$ of participants gave the correct answer. A low percentage of participants marked the patients' pain rating correctly as 8 on the numerical pain scale in both case studies $(20.1 \%$ and $2.6 \%$, respectively) even though the written description mentioned that the patient "rates his pain as 8 ".

Among the pharmacology-based items, 77.9\% of participants agreed that the opioid analgesic dose should be adjusted in accordance with the individual's response after the initial dose. $73.4 \%$ knew that combining analgesics that work by different mechanisms may result in better pain with fewer side effects than using just a single agent, 
Table I Socio-Economic Characteristics of the Study Participants $(N=154)$

\begin{tabular}{|c|c|c|}
\hline & Frequency (n) & Percentage (\%) \\
\hline \multicolumn{3}{|l|}{ Gender } \\
\hline Male & 31 & 20.1 \\
\hline Female & 123 & 79.9 \\
\hline \multicolumn{3}{|l|}{ Marital status } \\
\hline Single & 92 & 59.7 \\
\hline Married & 62 & 40.3 \\
\hline \multicolumn{3}{|l|}{ Educational level } \\
\hline Intermediate/Colleges & 104 & 67.5 \\
\hline University & 50 & 32.5 \\
\hline $\begin{array}{l}\text { Attending a formal course on } \\
\text { pain management }\end{array}$ & 88 & 57.1 \\
\hline \multicolumn{3}{|l|}{ Types of formal course } \\
\hline University lectures & 19 & 21.6 \\
\hline Postgraduate training & 36 & 40.9 \\
\hline Other & 33 & 37.5 \\
\hline $\begin{array}{l}\text { Other sources of information } \\
\text { on pain management }\end{array}$ & 109 & 70.8 \\
\hline \multicolumn{3}{|l|}{ Types of information sources } \\
\hline Books & 31 & 20.1 \\
\hline Internet & 35 & 22.7 \\
\hline Advice from expertise & 20 & 13.0 \\
\hline Training in the department & 44 & 28.6 \\
\hline $\begin{array}{l}\text { Using a pain assessment tool } \\
\text { in the hospital }\end{array}$ & 122 & 79.2 \\
\hline \multicolumn{3}{|l|}{$\begin{array}{l}\text { Frequency of using pain } \\
\text { assessment tools }\end{array}$} \\
\hline Never or seldom & 69 & 44.8 \\
\hline Sometimes & 61 & 39.6 \\
\hline Usually/Everyday & 24 & 15.6 \\
\hline $\begin{array}{l}\text { Having experiences on pain } \\
\text { management }\end{array}$ & 60 & 39.0 \\
\hline \multicolumn{3}{|l|}{$\begin{array}{l}\text { Self-assessing of pain } \\
\text { management skills }\end{array}$} \\
\hline Poor & 27 & 17.5 \\
\hline Average & 103 & 66.9 \\
\hline \multirow[t]{2}{*}{ Good } & 24 & 15.6 \\
\hline & Mean & SD \\
\hline Age (years) & 29.1 & 5.9 \\
\hline Working experience (years) & 5.6 & 4.4 \\
\hline
\end{tabular}

and $68.2 \%$ understood the meaning of the "equianalgesia" term. By contrast, only $28.6 \%$ of the participants knew the equivalent dose of a $30 \mathrm{mg}$ dose of oral morphine. In the two case studies, only $16.5 \%$ and $1.3 \%$ of the participants chose the correct options about what action to take with regard to IV morphine as needed for continued pain 2 hours after a dose of IV morphine. In terms of substance abuse/physical dependence, more than $70 \%$ of the participants knew about the recommendation of assessing sedation during opioid pain management (73.4\%) and the "narcotic/opioid addiction definition" (70.8\%). Only $30.5 \%$ understood the signs or symptoms of physical dependence when discontinuing an opioid.

Table 3 shows the factors related to the total KASRP score. Participants who attended a formal course in pain management or obtained information via university lectures were more likely to have higher KASRP scores. In terms of pain management information sources, knowledge acquired from books, advice from experts, or training in the department was positively associated with higher KASRP scores. The use of pain assessment tools usually/ everyday was also associated with higher KASRP scores.

Based on the results of the main study (154 participants), the Cronbach's alpha for the KASRP in our study was 0.768 , reflecting a high level of internal reliability.

\section{Discussion}

The main objective of our study was to evaluate the knowledge and attitudes of nurses toward pain management. The findings suggested deficient knowledge and an attitude gap about pain management among nurses working in a geriatric hospital, particularly with regard to pain assessment and the understanding of pharmacology related to pain management. Moreover, having attended formal courses on pain management, receiving information about pain management from other sources and using pain assessment tools frequently were associated with higher KASRP scores.

It is noteworthy that the overall scores from the tool we used showed that a high proportion of nurses had poor knowledge and negative attitudes regarding pain management $(72.2 \%)$. Our finding is consistent with previous studies that found a deficit in nursing knowledge and negative attitudes toward pain assessment and management ${ }^{13,20-23}$ Inadequate knowledge might be the result of insufficient pain management education. This is consistent with our research findings where only $12.3 \%$ of the nurses had been trained in pain management at medical universities. This suggests that our current undergraduate nursing curriculum is not preparing nurses to systematically assess pain, make sound nursing care decisions, and use pain relievers properly and effectively. In fact, the majority of the participants were intermediate/college 
Table 2 Percentage of Nurses with Correct Responses on Each Question of the KASRP $(n=154)$

\begin{tabular}{|c|c|c|c|}
\hline & & Frequency $(n)$ & Percentage (\%) \\
\hline & \multicolumn{3}{|l|}{ KASRP classification } \\
\hline & Poor knowledge and attitudes & $11 \mathrm{I}$ & 72.2 \\
\hline & Fair knowledge and attitudes & 43 & 27.8 \\
\hline \multirow[t]{2}{*}{ Item } & Content (correct answer) & Correct (n) & Accuracy (\%) \\
\hline & \multicolumn{3}{|l|}{ Cancer related pain } \\
\hline 25 & $\begin{array}{l}\text { Analgesic medications are considered for the treatment of prolonged moderate to severe pain for } \\
\text { cancer patients (morphine) }\end{array}$ & 128 & 83.1 \\
\hline 30 & Useful for treatment of cancer pain (All of the above) ${ }^{b}$ & 97 & 63.4 \\
\hline 5 & $\begin{array}{l}\text { Aspirin and other non-steroidal anti-inflammatory agents are NOT effective analgesics for painful } \\
\text { bone metastases }(F)^{\mathrm{a}}\end{array}$ & 84 & 54.6 \\
\hline 28 & $\begin{array}{l}\text { The likelihood of the patient developing clinically significant respiratory depression in the absence } \\
\text { of new comorbidity comorbidity (less than } 1 \%)^{b}\end{array}$ & 39 & 25.3 \\
\hline \multirow[t]{2}{*}{23} & $\begin{array}{l}\text { The recommended route of administration of opioid analgesics for patients with persistent cancer- } \\
\text { related pain (oral) }{ }^{\mathrm{b}}\end{array}$ & 9 & 5.8 \\
\hline & \multicolumn{3}{|l|}{ Pain assessment } \\
\hline 12 & $\begin{array}{l}\text { Children less than II years old cannot reliably report pain so clinicians should rely solely on the } \\
\text { parent's assessment of the child's pain intensity (F) }{ }^{a}\end{array}$ & 77 & 50.0 \\
\hline I & Vital signs are always reliable indicators of the intensity of a patients' pain $(F)^{a}$ & 76 & 49.4 \\
\hline 2 & $\begin{array}{l}\text { Because their nervous system is underdeveloped, children under two years of age have decreased } \\
\text { pain sensitivity and limited memory of painful experiences }(F)^{a}\end{array}$ & 65 & 42.2 \\
\hline 32 & $\begin{array}{l}\text { The best approach for cultural considerations in caring for patients in pain (Patients should be } \\
\text { individually assessed to determine cultural influences) }\end{array}$ & 64 & 41.6 \\
\hline 4 & Patients may sleep in spite of severe pain $(T)^{a}$ & 56 & 36.4 \\
\hline 3 & Patients who can be distracted from pain usually do not have severe pain $(F)^{a}$ & 45 & 29.2 \\
\hline 31 & The most accurate judge of the intensity of the patients' pain (the patient) ${ }^{b}$ & 39 & 25.3 \\
\hline $39 a$ & Case study $39 \mathrm{a}(8)^{\mathrm{b}}$ & 31 & 20.1 \\
\hline \multirow[t]{2}{*}{$38 \mathrm{~b}$} & Case study $38 \mathrm{a}(8)^{\mathrm{b}}$ & 4 & 2.6 \\
\hline & \multicolumn{3}{|l|}{ Pharmacology } \\
\hline 14 & $\begin{array}{l}\text { After an initial dose of opioid analgesic is given, subsequent doses should be adjusted in } \\
\text { accordance with the individual patients' response }(T)^{\mathrm{a}}\end{array}$ & 120 & 77.9 \\
\hline 7 & $\begin{array}{l}\text { Combining analgesics that work by different mechanisms (eg, combining an NSAID with an opioid) } \\
\text { may result in better pain control with fewer side effects than using a single analgesic agent }(T)^{a}\end{array}$ & 113 & 73.4 \\
\hline 13 & Patients' spiritual beliefs may lead them to think pain and suffering are necessary $(T)^{a}$ & 106 & 68.8 \\
\hline 21 & $\begin{array}{l}\text { The term "Equianalgesia" means approximately equal analgesia and is used when referring to the } \\
\text { doses of various analgesics that provide approximately the same amount of pain relief }(T)^{\mathrm{a}}\end{array}$ & 105 & 68.2 \\
\hline 10 & Elderly patients cannot tolerate opioids for pain relief $(F)^{a}$ & 100 & 64.9 \\
\hline 18 & Anticonvulsant drugs such as gabapentin (Neurontin) produce optimal pain relief after a single dose $(F)^{a}$ & 98 & 63.6 \\
\hline 19 & $\begin{array}{l}\text { Benzodiazepines are not effective pain relievers and are rarely recommended as part of an } \\
\text { analgesic regiment }(\mathrm{F})^{\mathrm{a}}\end{array}$ & 97 & 63.0 \\
\hline 24 & $\begin{array}{l}\text { The recommended route administration of opioid analgesics for patients with brief, severe pain of } \\
\text { sudden onset such as trauma or postoperative pain (intravenous) }\end{array}$ & 91 & 59.1 \\
\hline 29 & $\begin{array}{l}\text { The most likely reason a patient with pain would request increased doses of pain medication (The } \\
\text { patient is experiencing increased pain) }\end{array}$ & 84 & 54.6 \\
\hline 16 & $\begin{array}{l}\text { Vicodin (hydrocodone } 5 \mathrm{mg}+\text { acetaminophen } 300 \mathrm{mg} \text { ) PO is approximately equal to } 5-10 \mathrm{mg} \text { of } \\
\text { morphine PO }(\mathrm{T})^{\mathrm{a}}\end{array}$ & 82 & 53.3 \\
\hline 6 & $\begin{array}{l}\text { Respiratory depression rarely occurs in patients who have been receiving stable doses of opioids } \\
\text { over a period of months }(T)^{\mathrm{a}}\end{array}$ & 75 & 48.7 \\
\hline
\end{tabular}


Table 2 (Continued).

\begin{tabular}{|c|c|c|c|}
\hline & & Frequency (n) & Percentage $(\%)$ \\
\hline 34 & The time to peak effect for morphine given IV $(15 \mathrm{~min})^{\mathrm{b}}$ & 72 & 46.8 \\
\hline 27 & Analgesics for post-operative pain should initially be given (around the clock on a fixed schedule) & 69 & 44.8 \\
\hline 35 & The time to peak effect for morphine given orally $(\mathrm{I}-2 \text { hour })^{\mathrm{b}}$ & 64 & 41.6 \\
\hline 9 & Opioids should not be used in patients with a history of substance Abuse $(F)^{\mathrm{a}}$ & 62 & 40.3 \\
\hline 15 & Giving patients sterile water by injection (placebo) is a useful test to determine if the pain is real $(F)^{a}$ & 61 & 39.6 \\
\hline 37 & Opioid induced respiratory depression (Obstructive sleep apnea is an important risk factor) ${ }^{\mathrm{b}}$ & 56 & 36.4 \\
\hline 11 & Patients should be encouraged to endure as much pain as possible before using an opioid $(F)^{a}$ & 55 & 35.7 \\
\hline 8 & The usual duration of analgesia of $\mathrm{I}-2 \mathrm{mg}$ morphine IV is $4-5$ hours $(F)^{\mathrm{a}}$ & 54 & 35.1 \\
\hline 17 & $\begin{array}{l}\text { If the source of the patient's pain is unknown, opioids should not be used during the pain } \\
\text { evaluation period, as this could mask the ability to correctly diagnose the cause of pain }(F)^{a}\end{array}$ & 50 & 32.5 \\
\hline 26 & A $30 \mathrm{mg}$ dose of oral morphine is approximately equivalent to (Morphine $10 \mathrm{mg} \mathrm{IV})^{\mathrm{b}}$ & 44 & 28.6 \\
\hline $39 b$ & Case study $39 \mathrm{~b}$ (Administer morphine $3 \mathrm{mg}$ IV now) ${ }^{\mathrm{b}}$ & 25 & 16.5 \\
\hline \multirow[t]{2}{*}{$38 b$} & Case study $38 \mathrm{~b}$ (Administer morphine $3 \mathrm{mg}$ IV now) ${ }^{\mathrm{b}}$ & 2 & 1.3 \\
\hline & \multicolumn{3}{|l|}{ Substance abuse/physical dependence } \\
\hline 22 & $\begin{array}{l}\text { Sedation assessment is recommended during opioid pain management because excessive sedation } \\
\text { precedes opioid-induced respiratory depression }(T)^{\mathrm{a}}\end{array}$ & 113 & 73.4 \\
\hline 20 & $\begin{array}{l}\text { Narcotic/opioid addiction is defined as a chronic neurobiologic disease, characterized by behaviors } \\
\text { that include one or more of the following: impaired control over drug use, compulsive use, } \\
\text { continued use despite harm, and craving }(\mathrm{T})^{\mathrm{a}}\end{array}$ & 109 & 70.8 \\
\hline 33 & Patients develop pain already have an alcohol and/or drug abuse problem $(5-15 \%)^{\mathrm{b}}$ & 81 & 52.6 \\
\hline 36 & $\begin{array}{l}\text { Physical dependence is manifested by (sweating, yawning, diarrhea and agitation with patients when } \\
\text { the opioid is abruptly discontinued) }\end{array}$ & 47 & 30.5 \\
\hline
\end{tabular}

Notes: ${ }^{a}$ The item is a judgment question. $T$ stands for right and $\mathrm{F}$ stands for wrong. ${ }^{\mathrm{b}}$ The item is a single choice.

nurses and pain management is not included in their curriculum. Besides, this might be because of the lack of workshops or continuous education for nurses in the hospital as such courses depend on a donor resource. This finding is consistent with the findings of previous studies. ${ }^{23,24}$

The percentage of participants with correct answers for pain assessment was low. This finding may be because of nursing inexperience in pain assessment in clinical practice. The results of our study showed that $44.8 \%$ of the participants never or rarely used pain assessment tools. On the other hand, inadequate knowledge regarding pain management can be explained by the fact that nurses mainly rely on the patients' appearance or their behaviors in assessing the pain instead of what the patients report. ${ }^{25}$ These findings are consistent with previous studies indicating that nurses tended to underestimate patients' pain intensity and under-administer analgesics. ${ }^{13,20,26-28}$ In addition, the hospital has not had continuous pain management training for nurses, which may be one of the reasons for inadequate knowledge.

Deficits in knowledge and negative attitudes about pain medications were also found in our study. Similar to previous studies, knowledge about medications that effectively relieve the pain, the route of administration, tolerance, and side effects were mainly poor among the nurses. ${ }^{29,30}$ The participants showed better knowledge about adjusting opioid analgesics for patients after an initial dose, combining analgesics, the effectiveness of a single dose of anticonvulsant drugs, the effectiveness of benzodiazepines as pain relievers, and substance abuse/physical dependence related to the analgesic. However, we found insufficient knowledge in the areas of pharmacology (equivalent doses of analgesia, duration of the action of analgesia, types of analgesics for postoperative pain), opioid-induced respiratory depression and the doses of PRN morphine. Consistent with the finding from a previous study, a possible explanation is that our participants were not adequately trained in opioid doses, their adverse medical effects, and pharmacological knowledge. ${ }^{31}$ In Vietnam, nurses carry out physicians' orders with regard to pain medications and are less likely to make decisions about what pain medications to give, doses, and when to give pain medications as needed. This finding is supported by the findings of Adams et al and Lewthwaite et $\mathrm{al}^{23,32}$. 
Table 3 Factors Associated with a Total Score of the Knowledge and Attitudes Survey Regarding Pain (KASRP)

\begin{tabular}{|c|c|c|}
\hline & \multicolumn{2}{|c|}{$\begin{array}{l}\text { Total Score of } \\
\text { Knowledge and } \\
\text { Attitudes Survey } \\
\text { Regarding Pain }\end{array}$} \\
\hline & Coef & $95 \% \mathrm{Cl}$ \\
\hline Marital status (Ref: Single) & & \\
\hline Married & $-1.37 * *$ & $-2.46 ;-0.28$ \\
\hline $\begin{array}{l}\text { Attending a formal course on pain } \\
\text { management (Ref: No) }\end{array}$ & & \\
\hline Yes & $1.89 * * *$ & $0.54 ; 3.23$ \\
\hline Types of formal course (Ref: No) & & \\
\hline University lectures & $2.61 * * *$ & $0.76 ; 4.45$ \\
\hline Postgraduate training & 1.12 & $-0.35 ; 2.61$ \\
\hline $\begin{array}{l}\text { Other sources of information on pain } \\
\text { management (Ref: No) }\end{array}$ & & \\
\hline Yes & $1.51 * *$ & $0.26 ; 2.75$ \\
\hline Types of information sources (Ref: No) & & \\
\hline Books & $2.18^{* * *}$ & $0.7 I ; 3.65$ \\
\hline Internet & 0.92 & $-0.37 ; 2.22$ \\
\hline Advices from experts & $1.48 * *$ & $0.05 ; 2.90$ \\
\hline Training in the department & $1.53^{* *}$ & $0.21 ; 2.85$ \\
\hline $\begin{array}{l}\text { Frequency of using pain assessment } \\
\text { tools (Ref: Never or seldom) }\end{array}$ & & \\
\hline Usually/Everyday & $1.91 * *$ & $0.36 ; 3.46$ \\
\hline $\begin{array}{l}\text { Having experiences in pain } \\
\text { management (Ref: No) }\end{array}$ & & \\
\hline Yes & $1.93 * * *$ & $0.75 ; 3.10$ \\
\hline $\begin{array}{l}\text { Self-assessing of your pain } \\
\text { management skills (Ref: Poor) }\end{array}$ & & \\
\hline Average & -0.75 & $-1.78 ; 0.28$ \\
\hline
\end{tabular}

Notes: $* * * p<0.01, *^{*} p<0.05$.

Several recommendations can be drawn from this study. In this study, those who attended pain courses at medical universities, received information from books, pain experts, or training in departments, or frequently used pain assessment tools in the hospital had better knowledge and attitudes regarding pain management. This is encouraging as it suggests the provision of more education in pain management and more experience in the use of pain assessment tools can improve nurses' knowledge and attitudes with regard to pain. If pain assessments using appropriate tools were routinely used by nurses in hospital, nurses would increase their understanding of both the physiological and behavioral responses of patients to pain. ${ }^{33}$ The findings from our study suggest that hospitals should develop interdisciplinary approaches to manage pain, with clear lines of responsibility through more nursing education, which has shown good results in previous studies. ${ }^{32,34,35}$ Hospitals as well as the Ministry of Health need to provide guidance on the assessment and treatment of pain, especially in older people. On the other hand, our study suggests that different learning methods can be used, such as books, virtual reality lectures, online material and in-service programs that are appropriate for the content being taught. ${ }^{36}$ For graduate nurses, such as those who took part in this study, there is likely to be value in conducting regular learning activities about pain assessment and management with some of form of assessment and evaluation that allows for the modification and continued refinement of the education program. ${ }^{37}$ Finally, the findings of our research could form the basis of further studies, including both quantitative and qualitative research, with larger and more representative samples of healthcare workers in Vietnam.

Our study has several limitations. The cross-sectional study design limits the ability to establish causal relationships between the factors associated with the KASRP scores. Secondly, the specific study population is a limitation on the generalization our findings. Thirdly, the KASRP was designed for general nurses and not specifically for nurses working with older people. This would require the development of a tool specifically to assess the knowledge and attitudes to pain in older people.

\section{Conclusion}

This study highlights significant deficits of knowledge and negative attitudes regarding pain management among nurses working in a geriatric hospital. It is recommended that the subject of pain and its management be applied and enhanced in continuous education and the nursing undergraduate curriculum. Nurses' active participation in pain management should be encouraged and pain assessment tools should be routinely used by healthcare providers for older patients who report pain in clinical practice. Further studies are needed to assess the changes in knowledge and attitudes toward pain as curricular revisions are made.

\section{Abbreviation}

KASRP, Knowledge and Attitudes Survey Regarding Pain. 


\section{Data Sharing Statement}

The datasets of this study are available from the corresponding author on reasonable request.

\section{Ethics Approval and Informed Consent}

The study was approved by the Ethics Committee of the National Geriatric Hospital Review Board (635/IRBNGH) and Hanoi Medical University (63/IRB-HMU). Participants were explained clearly about the purpose of the study before participating. The purpose of the study was explained clearly to the participants before they took part. The participants had the right to not participate in or withdraw from the study at any time. Written informed consent was obtained from all participants. The questionnaire did not include any private information for or anything of harm to the participants. The results of the research were used for the study purposes only.

We confirm that our study complied with the Declaration of Helsinki.

\section{Acknowledgments}

We would like to express our deepest gratitude for the great support of the National Geriatric Hospital, Hanoi, Vietnam during research implementation.

\section{Author Contributions}

All the authors made substantial contributions to the conception and design, acquisition of data, and/or analysis and interpretation of data; took part in drafting the article or revising it critically for important intellectual content; agreed on the journal to which the article will be submitted; gave final approval of the version to be published; and agree to be accountable for all aspects of the work.

\section{Funding}

For the conducting process and data entry, this work was supported partly by the Hanoi Medical University fund.

\section{Disclosure}

The authors report no conflicts of interest in this work.

\section{References}

1. World Health Organization. The world's population is rapidly ageing 2018. Geneva; 2018.

2. World Health Oranization. World population ageing 2019: highlights. New York, USA; 2019.
3. News VN. Việt Nam prepares to support aging population 9/9/2017. Available from: https://vietnamnews.vn/society/health/393500/viet$\mathrm{n}$ a m-prepare s-to-s u p port-a gin g-populat i on . html\#zVbpPrxDy9wgVgRC.97. Accessed March 25, 2021.

4. Ferrell BA, Ferrell BR, Osterweil D. Pain in the nursing home. $J \mathrm{Am}$ Geriatr Soc. 1990;38(4):409-414. doi:10.1111/j.1532-5415.1990.tb035 38.x

5. Rumble RH, Morgan K. Longitudinal trends in prescribing for elderly patients: two surveys four years apart. $\mathrm{Br} J$ Gen Pract. 1994;44(389):571-575.

6. Maxwell CJ, Dalby DM, Slater M, et al. The prevalence and management of current daily pain among older home care clients. Pain. 2008;138(1):208-216.

7. Ckowicz E, Ferrell B, Casarett D. The management of persistent pain in older persons. J Am Geriatr Soc. 2002;50(6 Suppl):S205.

8. Bosley BN, Weiner DK, Rudy TE, Granieri E. Is chronic nonmalignant pain associated with decreased appetite in older adults? Preliminary evidence. J Am Geriatr Soc. 2004;52(2):247-251. doi:10.1111/j.1532-5415.2004.52063.x

9. Goldstein NE, Morrison RS. Treatment of pain in older patients. Crit Rev Oncol Hematol. 2005;54(2):157-164. doi:10.1016/j.critrevonc. 2005.01.001

10. Ferrell BA, Ferrell BR, Rivera L. Pain in cognitively impaired nursing home patients. J Pain Symptom Manage. 1995;10(8):591-598. doi:10.1016/0885-3924(95)00121-2

11. Lewis SL, Heitkemper MM, Dirksen SR, O'Brien PG, Bucher L. Medical-Surgical Nursing-Assessment and Management of Clinical Problems. $7^{\text {th }}$ ed. Mosby; 2007:125-150

12. Samarkandi OA. Knowledge and attitudes of nurses toward pain management. Saudi J Anaesth. 2018;12(2):220-226. doi:10.4103/ sja.SJA_587_17

13. Al-Khawaldeh OA, Al-Hussami M, Darawad M. Knowledge and attitudes regarding pain management among Jordanian nursing students. Nurse Educ Today. 2013;33(4):339-345. doi:10.1016/j. nedt.2013.01.006

14. Sloman R, Ahern M, Wright A, Brown L. Nurses' knowledge of pain in the elderly. J Pain Symptom Manage. 2001;21(4):317-322. doi:10.1016/S0885-3924(01)00248-2

15. Thi Thanh Vu H, Hoang NL, Xuan NT, et al. Knowledge and attitude toward geriatric palliative care among health professionals in Vietnam. Int J Environ Res Public Health. 2019;16(15).

16. Ferrell B, McCaffery M. Knowledge and attitudes survey regarding pain. City of hope pain \& palliative care resource center; [Updated July 2014]. Available from: https://www.midss.org/content/knowl edge-and-attitudes-survey-regarding-pain-kasrp. Accessed March 31, 2021.

17. Kipkorir C. Knowledge and attitudes of nurses towards pain management among the elderly: a case study of registered nurses from the local healthcare centers. Kokkola; 2012.

18. Betty Ferrell MM. Knowledge and attitudes survey regarding pain; 2014.

19. Shdaifat E, Al-Shdayfat N, Sudqi A. Saudi nursing students' pain management knowledge and attitudes. Nurs Open. 2020;7(6):1833-1839. PMID: 33072368; PMCID: PMC7544852. doi:10.1002/nop2.570.

20. Rahimi-Madiseh M, Tavakol M, Dennick R. A quantitative study of Iranian nursing students' knowledge and attitudes towards pain: implication for education. Int $J$ Nurs Pract. 2010;16(5):478-483. doi:10.1111/j.1440-172X.2010.01872.x

21. Issa MR, Awajeh AM, Fs K. Knowledge and attitude about pain and pain management among critical care nurses in a tertiary hospital. J Intensive Crit Care. 2017;3(1).

22. Karamjeet K. Knowledge and attitude regarding pain management among staff nurses. Nurse Care Open Acces J. 2017;2(1):5-7. doi:10.15406/ncoaj.2017.02.00024

23. Adams S-DM, Varaei S, Jalalinia F. Nurses' knowledge and attitude towards postoperative pain management in Ghana. Pain Res Manage. 2020;2020:7. doi:10.1155/2020/4893707 
24. Basak S. Knowledge and attitudes of nurses and their practices regarding postoperative pain management in Bangladesh. Hat Yai, Thailand: Prince of Songkla University; 2010.

25. Kim HS, Sjöström B, Schwartz-Barcott D. Pain assessment in the perspective of action science. Res Theory Nurs Pract. 2006;20 (3):215-228. PMID: 16986355. doi:10.1891/rtnp.20.3.215.

26. Van Dijk JF, Schuurmans MJ, Alblas EE, Kalkman CJ, van Wijck AJ. Postoperative pain: knowledge and beliefs of patients and nurses. J Clin Nurs. 2017;26(21-22):3500-3510. PMID: 28042880. doi:10.1111/ jocn. 13714

27. Duke G, Haas BK, Yarbrough S, Northam S. Pain management knowledge and attitudes of baccalaureate nursing students and faculty. Pain Manag Nurs. 2013;14(1):11-19. doi:10.1016/j. pmn.2010.03.006

28. Comley AL, Banks JC. Pain management: clinician survey and institutional needs assessment. Proc. 2000;13(3):230-235. doi:10.1080/08998280.2000.11927680

29. Plaisance L, C. L. Nursing students' knowledge and attitudes regarding pain. Pain Manag Nurs. 2006;7(4):167-175. doi:10.1016/j. pmn.2006.09.003

30. Toba HA, Samara AM, Sh Z. Nurses' knowledge, perceived barriers, and practices regarding cancer pain management: a cross-sectional study from Palestine. BMC Med Educ. 2019;19(1):167. doi:10.1186/ s12909-019-1613-z

31. Fallatah SMA. Pain knowledge and attitude survey among health-care professionals at a university hospital in Saudi Arabia. Saudi J Med Med Sci. 2017;5(2):155-159. doi:10.4103/1658-631X.204855
32. Lewthwaite BJ, Jabusch KM, Wheeler BJ, et al. Nurses' knowledge and attitudes regarding pain management in hospitalized adults. J Contin Educ Nurs. 2011;42(6):251-257. doi:10.3928/0022012420110103-03

33. Gordon DB, Dahl JL, Miaskowski C, et al. American pain society recommendations for improving the quality of acute and cancer pain management: American pain society quality of care task force. Arch Intern Med. 2005;165(14):1574-1580. doi:10.1001/archinte.165. 14.1574

34. Wong M. Medical nurses' knowledge and attitudes regarding pain management: university of British Columbia; 2012.

35. Huth MM, Gregg TL, Lin L. Education changes Mexican nurses' knowledge and attitudes regarding pediatric pain. Pain Manage Nurs. 2010;11(4):201-208. doi:10.1016/j.pain.2008.04.007

36. Wells N, Pasero C, McCaffery M. Improving the quality of care through pain assessment and management. In: Hughes RG, editor. Patient Safety and Quality: An Evidence-Based Handbook for Nurses. Advances in Patient Safety. Rockville (MD); 2008.

37. American Pain Society Quality of Care Committee. Quality improvement guidelines for the treatment of acute pain and cancer pain. JAMA. 1995;274(23):1874-1880. doi:10.1001/jama.1995.03530230 060032
Journal of Multidisciplinary Healthcare

\section{Publish your work in this journal}

The Journal of Multidisciplinary Healthcare is an international, peerreviewed open-access journal that aims to represent and publish research in healthcare areas delivered by practitioners of different disciplines. This includes studies and reviews conducted by multidisciplinary teams as well as research which evaluates the results or conduct of such teams or healthcare processes in general. The journal

\section{Dovepress}

covers a very wide range of areas and welcomes submissions from practitioners at all levels, from all over the world. The manuscript management system is completely online and includes a very quick and fair peer-review system. Visit http://www.dovepress.com/testimonials. php to read real quotes from published authors. 